\title{
The association between brain volume and intelligence is of genetic origin
}

TO THE EDITOR-The recent study by Thompson and colleagues ${ }^{1}$ reported high heritability of gray-matter volume in several cortical regions using voxel-based M RI techniques. Gray matter substantially correlated with general intelligence, or ' $g$ '. These findings prompt three major questions: (i) is the high heritability specific to gray-matter volume, (ii) is the correlation with g specific to gray-matter volume and (iii) is the correlation between gray-matter volume and $g$ of genetic or environmental origin?

We addressed the first question in a large Dutch sample of twins and their siblings (258 Dutch adults from 112 extended twin families) ${ }^{2}$. We found high heritability for total brain gray-matter volume (Table 1), comparable to the estimate reported by Thompson and colleagues ${ }^{1}$. In addition, we found high heritability for total brain white-matter volume.

As stated in a commentary ${ }^{3}$ on the recent report in Nature N euroscience ${ }^{1}$, high heritability of gray matter implies that interindividual variation in cell-body volume is not modified by experience. Because white matter reflects the degree of interconnection between different neurons, interindividual variance in whitematter volume might be expected to be more under the influence of experience and less under genetic control. Our results clearly suggest otherwise. Either environmental experience barely contributes to interindividual variation in white-matter volume or, alternatively,

\section{Table 1. Heritability estimates from multivariate genetic analyses}

\begin{tabular}{lc}
\hline & Heritability \\
W hole-brain gray matter & 0.82 \\
W hole-brain white matter & 0.87 \\
G eneral intelligence ( $\mathrm{g})^{\text {a }}$ & 0.86 \\
W orking memorya & 0.67 \\
& \\
\hline aW AIS-IIIR IQ test. & \\
D etails of brain imaging methods and subject \\
characteristics of the MRI sample (258 subjects \\
from 112 extended twin families) have been \\
described previously ${ }^{2}$, as have detailed \\
characteristics of the W AIS-IIIR sample (688 \\
subjects from 271 extended twin families) ${ }^{4}$. The \\
overlapping dataset consisted of 135 subjects \\
from 60 extended twin families (24 MZ pairs, \\
31 D Z pairs and 25 additional siblings).
\end{tabular}

exposure to relevant environmental experience is under strong genetic control.

The subjects for whom M RI scans were available partly overlapped with a sample of extended twin families from a large study on cognition ${ }^{4}$. In thelatter study, we found a heritability of $g$ of 0.86 , which is consistent with previous reports 5 . We have now confirmed a correlation between gray-matter volume and $g(0.25 ; p<0.05)$ and, in addition, have found a significant correlation between white-matter volume and $g(0.24 ; p<0.05)$. Thus, regarding the first two questions, we conclude that white-matter volumeis also highly heritable and that $g$ is related to the volumes of both gray and white matter.

In twin samples of sufficient size, the correlation between brain volume and $g$ can be decomposed into genetic and environmental components ${ }^{6}$. Such analysis is based on the comparison of cross-trait/cross-twin correlations for monozygotic (M Z) and dizygotic (DZ) twins (or sibling pairs). If the correlation between brain volume of a twin and $g$ in the co-twin is larger in M Z than in DZ twins, this indicates that the genes influencing brain volume partly overlap with the genes that influence g. The extent of the overlap is reflected by the magnitude of the genetic correlation. When the cross-trait/cross-twin correlations are similar for MZ and DZ twins, this suggests that environmental factors contribute to the observed phenotypic correlation between brain volume and $\mathrm{g}$. Given a heritability of 0.85 for brain volume $^{2}$, a heritability of 0.80 for $g$ (ref. 5) and a correlation between brain volume and $g$ of 0.40 (ref. 7), at least $17 \mathrm{MZ}$ and $17 \mathrm{DZ}$ pairs are needed to detect a genetic correlation with $80 \%$ power (and $\alpha=$ 0.05 ) that explains the observed correlation.

In $24 \mathrm{M} \mathrm{Z}$ pairs, $31 \mathrm{DZ}$ pairs and 25 additional siblings, we decomposed the correlation between brain volumes and $g$ into genetic and environmental components by using structural equation modeling for a multivariate genetic design ( gray matter, white matter and g) ${ }^{6}$. This showed that the correlation between gray-matter volume and g was due completely to genetic factors and not to environmental factors. We obtained the same result for the corre lation between white matter volume and g. Thus, the answer to thethird question is

Table 2. O bserved (phenotypic) correlations, cross-trait/cross-twin correlations, genetic correlations and environmental correlations

\begin{tabular}{|c|c|c|c|c|}
\hline & \multicolumn{4}{|c|}{ Correlation } \\
\hline & O bserved & $\begin{array}{l}\text { MZ cross-trait/ } \\
\text { cross-twin }\end{array}$ & $\begin{array}{l}\text { DZ cross-trait/ } \\
\text { cross-twin }\end{array}$ & Genetic \\
\hline W hole-brain gray matter-g & $0.25^{*}$ & $0.26 *$ & 0.14 & $0.29 *$ \\
\hline $\begin{array}{l}\text { W hole-brain gray matter- } \\
\text { W orking memory }\end{array}$ & $0.29 *$ & $0.32 *$ & $0.20 *$ & $0.38 *$ \\
\hline W hole-brain white matter-g & $0.24 *$ & $0.22 *$ & 0.19 & $0.24 *$ \\
\hline $\begin{array}{l}\text { W hole-brain white matter- } \\
\text { W orking memory }\end{array}$ & $0.29 *$ & $0.27 *$ & 0.19 & $0.35^{*}$ \\
\hline \multicolumn{5}{|c|}{$\begin{array}{l}\text { *Significantly different from zero at the } \alpha=0.05 \text { level. } \\
\text { MZ, monozygotic twins; DZ, dizygotic twins, including sibling pairs. The cross-trait/cross-twin correla- } \\
\text { tions in MZ pairs showed evidence for a genetic mediation between brain volumes and g(and its } \\
\text { working-memory component); the cross-trait/cross-twin correlation for MZ pairs was as high as the } \\
\text { correlation between brain volume and g(or working memory) within the same person. In other } \\
\text { words, the IQ of MZ twins was predicted equally well from the size of the brain of their co-twins as } \\
\text { from the size of their own brain. All analyses were carried out using maximum likelihood estimation } \\
\text { implemented in Mx software } 11 \text {. Mx is especially suited to handle incomplete data structures, as is } \\
\text { the case when not all variables have been measured in all subjects. Effects of sex and age have been } \\
\text { regressed out on the observed scores. O bserved correlations and cross-trait/cross-twin correlations } \\
\text { were estimated from a saturated model in which the (co-) variances are not decomposed, whereas the } \\
\text { genetic and environmental correlations were estimated from a multivariate genetic design in which the } \\
\text { (co-) variances are decomposed into genetic and environmental components. The 'genetic correlation' } \\
\text { reflects the correlation between the set of genes that influences brain volume and the set of genes that } \\
\text { influences intelligence. The 'genetic contribution to the obser ved correlation' can be derived as the } \\
\text { product of the genetic correlation and the square roots of the heritabilities of the two phenotypes. }\end{array}$} \\
\hline
\end{tabular}


that the correlation between brain volumes and $g$ is, as anticipated ${ }^{8}$, mediated entirely by genetic factors (Table 2).

As our measure of $g$ consisted of the IQ score on the WAIS-IIIR IQ test, we were also interested in whether a particular dimension of g correlated more highly with gray- and white matter volume than any other dimension. The four standard WAIS-IIIR dimensions are Verbal Comprehension, Perceptual Organization, Processing Speed, and Working M emory. We found that the Working M emory dimension had the highest phenotypic and highest genetic correlation with brain volumes. This is perhaps not surprising, because working memory is considered a major component of $g$ (ref. 9). Also, working memory is often 'localized' in the frontal lobes $^{10}$, which provides further convergence between our findings and those of Thompson and colleagues ${ }^{1}$.

Establishing that the correlation between brain volumes and $g$ is mediated by common genetic factors is only the first step in unveiling the relation between them. The next step will be to identify specific genes that influence both brain volume and $g$.

\section{Daniëlle Posthuma ${ }^{1}$, \\ Eco J. C. De Geus ${ }^{1}$, Wim F. C. Baaré2 Hilleke E. Hulshoff Pol2, \\ René S. Kahn ${ }^{2}$ and \\ Dorret I. Boomsma ${ }^{1}$}

1 Department of Biological Psychology, Vrije Universiteit Amsterdam, van der Boechorststraat 1, 1081 BT, Amsterdam, The N etherlands

e-mail: d.posthuma@psy.vu.nl

2 Department of Psychiatry, University M edical Centre, Heidelberglaan 100, 3584

CX Utrecht, The N etherlands

1. Thompson, P. M. et al. Nat. Neurosci. 4, 1253-1258 (2001).

2. Baaré, W. F. C. et al. Cereb. Cortex 11, 816-824 (2001).
3. Plomin, R. \& Kosslyn, S. M. Nat. N eurosci. 4, 1153-1155 (2001)

4. Posthuma, D., De Geus, E. J. C. \& Boomsma, D. I. Behav. Genet. 31, 593-602 (2001).

5. Plomin, R., Defries, J. C., Craig, I. W. \& McGuffin, P. (eds). Behavioral Genetics in a Postgenomic Era (APA Books, Washington, $D C$, in press).

6. Neale, M. C. \& Cardon, L. R. M ethodology for Genetic Studies of Twins and Families, NATO Asi Series, Ser. D, Behavioural and Social Sciences, Vol. 67 (Kluwer, Dordrecht, The Netherlands, 1992).

7. Vernon, P. A., Wickett, J. C., Banzana, P. G. \& Stelmack, R. M. in Handbook of Intelligence (ed. Sternberg, R. J.) 245-264 (Cambridge Univ. Press, 2000).

8. Pennington, B. C. et al. J. Cogn. Neurosci. 12 223-232 (2000)

9. Daneman, M.\& Merikle, P. M. Psychon. Bull. Rev. 3, 422-433 (1996)

10. Goldman-Rakic, P. S. Proc. Natl. Acad. Sci. USA 93, 13473-13480 (1996).

11. Neale, M. C. M x: Statistical M odeling 3rd edn. (Medical College of Virginia, Richmond, VA 1997).

We welcome short letters on matters arising from previous papers in Nature Neuroscience or on other topics of widespread interest to the neuroscience community. Because space in this section of the journal is limited, priority is given to short (fewer than 500 words), well-written letters addressing the most topical issues. Typically, new data are not presented in this section, although they may occasionally be allowed at the discretion of the editors. Letters concerning material previously published in Nature Neuroscience are usually sent to the authors of the original piece for their comments and/or a formal reply. Letters may be edited for brevity and clarity. 